\title{
Transcriptomics Analysis of Daheng Broilers Reveals that PLIN2 Regulates Chicken Preadipocyte Proliferation, Differentiation and Apoptosis
}

\section{Jingjing Li}

Sichuan Agricultural University - Chengdu Campus

\section{Chaowu Yang}

Sichuan Animal Sciences Academy

\section{Peng Ren}

Southwest University of Science and Technology

\section{Zhongzhen Lin}

Sichuan Agricultural University - Chengdu Campus

\section{Donghao Zhang}

Sichuan Agricultural University - Chengdu Campus

\section{Xiaosong Jiang}

Sichuan Animal Sciences Academy

\section{Li Wang}

Sichuan Agricultural University - Chengdu Campus

Yiping Liu ( $\nabla$ liuyp578@163.com )

Sichuan Agricultural University - Chengdu Campus

\section{Research Article}

Keywords: chicken, intramuscular fat, meat quality, transcriptomics, PLIN2

Posted Date: July 30th, 2021

DOI: https://doi.org/10.21203/rs.3.rs-720408/v1

License: (c) (1) This work is licensed under a Creative Commons Attribution 4.0 International License.

Read Full License

Version of Record: A version of this preprint was published at Molecular Biology Reports on October 29th, 2021. See the published version at https://doi.org/10.1007/s11033-021-06831-x. 


\section{Abstract}

Intramuscular fat content, an important meat quality trait, strongly affects flavor, juiciness, and tenderness. Sex hormones regulate lipid metabolism, and female hormones stimulate fat deposition, thereby making the female chickens always fatter than males. In this study, the effect of sex on IMF deposition was screened following transcriptomics in chickens. Results confirmed significantly higher IMF content of 150-day female chickens as compared to the male chickens. The female chickens manifested higher serum TG, LDL-C, and VLDL, and significantly lower HDL-C contents than male chickens. Moreover, differential expression of genes involved in lipid metabolism were obtained in the muscle and liver between female and male chicken, which could partly interpret the possible reasons for the sex-mediated differences of IMF content. Cellular results revealed that inhibition of PLIN2 significantly inhibited chicken preadipocyte proliferation and induces apoptosis of preadipocytes, as well as promoted adipocyte differentiation.

\section{Introduction}

During the past few decades, a notable increase has been experienced in the demand for poultry meat (Petracci et al. 2015). As far as nutrition is concerned, poultry meat, particularly breast meat, quench the demand of the modern consumer for a high degree of unsaturation fatty acids and low fat, sodium, and cholesterol levels (Petracci and Cavani 2012). Nowadays, the importance of meat quality in the poultry industry could be validated by the enhanced sale of chicken meat as parts or further-processed products (Li et al. 2019). Intramuscular fat (IMF) refers to the amount of lipids deposited within the muscle, including myometrium, myofibrils, and endometrium. It mostly comprises triglycerides (TGs), phospholipids, and cholesterol (Liu et al. 2019). Among the meat quality traits, the major role is played by the content of IMF owing to its strong effect on flavor, juiciness, and tenderness (Zerehdaran et al. 2004; Hocquette et al. 2010; Warner et al. 2010). Previous observations substantiated the impact of sex hormones in regulating lipid metabolism, and female hormones stimulated fat deposition are responsible for the fact that female chickens are always fatter than males (Gawrieh 2015). Importantly, higher IMF content is always associated with higher plasma lipid and fatty acid metabolism related gene expression (Saez et al. 2009; Chen et al. 2017).

Transcriptome encompasses the pool of all gene transcripts transcribed from a tissue or cell at a certain developmental stage or functional state (Yin et al. 2019). With expanded knowledge on the extent and complexity of transcriptomes, RNA sequencing (RNA-Seq) has been established as one of the powerful next-generation sequencing techniques (Wang et al. 2011). Thus far, RNA-Seq has elucidated the mechanism of lipid deposition in bull (Jeong et al. 2013), sheep (Miao et al. 2015), Squabs (Ye et al. 2016), and pig (Ramayo-Caldas et al. 2012). Many candidate genes attributed to chicken lipid metabolism have been identified, such as fatty acid binding protein (FABP) (Shi et al. 2010), peroxisome proliferator-activated receptor- $\gamma$ (PPARY) (Royan and Navidshad 2016), follicle-stimulating hormone receptor (FSHR) (Cui et al. 2012a). Although, previous studies have analyzed the transcriptome of chicken breast muscle (Cui et al. 2012b), and identified some potential candidate genes. However, the molecular 
mechanisms underlying chicken IMF deposition have not been fully elucidated and further validation need to be performed.

The present study was conducted to: (1) demonstrate the differences of IMF content and serum lipid level between male chickens and female chickens; (2) identify candidate genes involved in the lipid metabolism through transcriptome analysis of muscle and liver tissues between female chickens and male chickens; (3) explore the function of the differentially expressed gene between female chickens and male chickens in chicken primary intramuscular preadipocytes.

\section{Materials And Methods}

\section{Animals}

A total of 200 1-day-old female and male Da-Heng broilers were reared in the Sichuan Da-Heng Poultry Breeding Company (Chengdu, China) with one cage for each bird. All birds were simultaneously enrolled for the experiment and were kept under the same management system with free access to feed and water at all times. The experiments were conducted following national institutes of health guide for the care and use of laboratory animals. At the rearing period of 150 days of age, 3 female chickens and 3 male chickens were randomly selected for sample collection. Before slaughtering, birds were deprived of feed overnight (12 h) but provided with water. All the experiments were performed in accordance with the principles and procedures outlined by Sichuan Agricultural University's Animal Care and Use Committee.

\section{Sample collection}

A total of $2 \mathrm{~mL}$ of blood was drained from the brachial vein. After breathing anesthesia until unconsciousness, the birds were sacrificed by cutting the carotid arteries. After slaughter, roughly $1-2 \mathrm{~g}$

of pectoral muscle samples (on the left side) and liver were rapidly sampled and immediately snap-frozen using liquid nitrogen and stored at $-80^{\circ} \mathrm{C}$ until they were analyzed using RNA-seq technology. To determine the intramuscular fat content, the left breast muscles were quickly frozen at $-20^{\circ} \mathrm{C}$. Meanwhile, 13 tissues of three female chicken were also collected and immediately snap-frozen in liquid nitrogen. All tissues were stored at $-80^{\circ} \mathrm{C}$ until RNA isolation.

\section{Serum Lipid Measurement and IMF content determination}

The blood was incubated at room temperature for $1 \mathrm{~h}$. Thereafter, serum was separated by centrifugation at $1500 \mathrm{~g} / \mathrm{min}$ for $15 \mathrm{~min}$. The serum was stored at $-80^{\circ} \mathrm{C}$ in glass tubes to prevent oxidative degradation. The levels of serum triglycerides (TG), total cholesterol (TC), high density lipoprotein (HDL), low-density lipoprotein $(L D L)$, and very low-density lipoprotein $(V L D L)$ were estimated by colorimetric enzymatic methods with the help of commercial kits purchased from Nanjing Jiancheng Bioengineering Institute (Nanjing, China).

For the determination of IMF content, breast muscles were homogenized individually in a meat grinder after being thawed. About $20 \mathrm{~g}$ of muscle were weighed and dried at $105^{\circ} \mathrm{C}$ for $12 \mathrm{~h}$, followed by cooling 
in a desiccator for $12 \mathrm{~h}$. The IMF contents in breast muscles were measured by placing dried samples into a Soxhlet extraction device (VELP Scientifica, SER 148, Usmate, Italy) and extracted for $24 \mathrm{~h}$. The results were expressed as percentages.

\section{RNA extraction and transcriptome analysis}

The RNA-Seq analysis involved three animals from female chickens and male chickens. Total RNA was isolated from the tissues and cells with the help of TRIzol total RNA extraction kit (Invitrogen, Carlsbad, USA) following the manufacturer's instructions. Agilent 2100 Bioanalyzer (Agilent Technologies) and agarose gel electrophoresis were conducted to validate the integrity of RNA. The purity of RNA was determined by the NanoPhotometer spectrophotometer (Thermo Scientific). Only qualified RNA samples were considered acceptable for sequencing.

FastQC v0.10.1 was adopted to estimate the quality of the raw data. Removal of adapter sequences and low-quality sequences would clean the raw data, which were then mapped to the reference genome of Gallus 5.0 using HISAT v2.2.4. Differentially expressed genes (DEGs) were identified by comparing the fragments per kilobase per million reads (FPKM) of two groups using DESeq2. The genes with a false

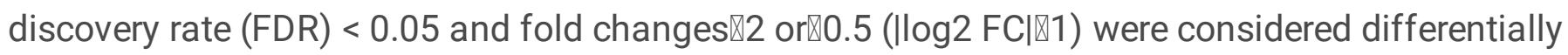
expressed genes (DEGs). Kyoto Encyclopedia of Genes and Genomes (KEGG) pathway enrichment of the DEGs was explored using the DAVID database (http://david.abcc.ncifcrf.gov/) (Dennis et al. 2003). The calculated $p$-value was gone through FDR Correction, taking FDR $\leq 0.05$ as a threshold.

\section{cDNA synthesis and real-time qRT-PCR analysis}

The PrimeScript ${ }^{\text {TM }}$ RT Reagent Kit was employed for the reverse transcription of total RNA. Primers used for quantitative real-time (qRT-PCR) were listed in Table 1. The qRT-PCR was conducted in a CFX-96 (BioRad, Inc., Richmond, CA, USA) qRT-PCR system using a $10 \mu \mathrm{L}$ reaction volume with $1 \mu \mathrm{L}$ of CDNA, $0.5 \mu \mathrm{L}$ of the forward and reverse primers $(10 \mu \mathrm{M})$ for each gene, $5 \mu \mathrm{L}$ of TB Green Premix Ex Taq (Tli RNase H Plus) (TaKaRa), and $3 \mu \mathrm{L}$ of double-distilled $\mathrm{H}_{2} \mathrm{O}$. All mRNA expression levels were normalized to GAPDH mRNA level, thereafter computing the mean expression level in each group.

\section{Chicken primary intramuscular preadipocyte isolation, culture, and induction of differentiation}

Chicken primary intramuscular preadipocytes were isolated from two-week-old Daheng female chickens using the method described by Zhang et al., with some modifications (Zhang et al. 2018). In brief, breast muscle tissues were collected under sterile conditions, followed by washing with phosphatebuffered saline (PBS) supplemented 1\% penicillin-streptomycin (Solarbio, Beijing, China). The washed tissue was minced into $1-\mathrm{mm}^{3}$ pieces using surgical scissors and digested for $1.5 \mathrm{~h}$ using a mixture of collagenase type I and collagenase type II (Solarbio, Beijing, China). After filtering the digested cell suspension with 200-and 500-mesh screens, centrifugation was done at $1000 \mathrm{rpm}$ for $10 \mathrm{~min}$. After adherence for $2 \mathrm{~h}$, intramuscular adipocytes were plated onto a $60-\mathrm{mm}$ culture plate at a density of $1 \times$ $10^{5}$ cells/mL. Cells were expanded in Dulbecco's modified Eagle medium (DMEM; Gibco, Australia), 
supplemented with $10 \%$ fetal bovine serum (FBS; Gibco, Grand Island, NY, USA), and 1\% penicillinstreptomycin. On reaching 80-90\% confluency, cells were exposed to an induced differentiation medium consisting of growth medium supplemented with $0.5 \mathrm{mM}$ 3-isobutyl-1-methylxanthine (IBMX), $1 \mu \mathrm{M}$ dexamethasone (DEX), $10 \mu \mathrm{g} / \mathrm{mL}$ insulin (INS), and $300 \mu \mathrm{M}$ oleate (dissolved in DMSO) (Sigma).

\section{Cell transfection}

Cultivated in 6-well plates, cells were transfected with PLIN2-siRNAs (sense: GCUGGUGAUGUCUACGAAATT; antisense: UUUCGUAGACAUCACCAGCTT) (Sangon Biotech, Shanghai, China) when the fusion degree of myoblasts reached 70\%. The Lipofectamine 3000 Reagent (Invitrogen, USA) was used as a transfection reagent, and cells were harvested after $48 \mathrm{~h}$.

\section{Cell proliferation and apoptosis assays}

Cell counting kit-8 (CCK-8) and 5-Ethynyl-20-Deoxyuridine (EdU) assays were used to evaluate the cell proliferation activity. For the CCK-8 assay, the cells were seeded in 96 -well plates, and after $0,12,24,36$, and $48 \mathrm{~h}$ of transfection, $10 \mu \mathrm{L}$ of cck-8 (Bestbio, Shanghai, China) was added and incubated for $2 \mathrm{~h}$ at $37 \circ \mathrm{C}$, and the absorbance was measured using a Model 680 Microplate Reader (Bio-Rad, Hercules, CA, USA) by optical density at a wavelength of $450 \mathrm{~nm}$. For the EdU assay, cells were seeded in 96-well plates and transfected when they reached to a density of approximately $50 \%$. After transfection for $48 \mathrm{~h}$, the cells were exposed to $50 \mu \mathrm{M}$ EdU (Ribobio, Guangzhou, China) for $2 \mathrm{~h}$ at $37^{\circ} \mathrm{C}$. After that, the cells were fixed and stained with Apollo and Hoechst 33,342 according to the manufacturer's instructions. Finally, we used a fluorescence microscope (OLYMPUS, Tokyo, Japan) to capture three fields which randomly selected and the number of stained cells was counted by the Image-Pro Plus 6.0 software. Additionally, to evaluate the effect of PLIN2 on apoptosis, Apoptosis and Necrosis Assay Kit (Beyotime; catalog number: C1056) was used following the manufacturer's instructions.

\section{Oil red 0 staining and quantification}

The muscle tissues were sectioned with a freezing microtome, fixed with $4 \%$ paraformaldehyde for 15 min, stained with Oil Red $O$ (Servicebio, Wuhan, China) for 10 min at room temperature and then visualized under a microscope. Cells were washed with PBS three times and fixed with $10 \%$ formaldehyde for $30 \mathrm{~min}$. Each slice within each group was randomly selected 3 images in the field of vision. For cellular Oil Red 0 staining, cells were washed with PBS twice and fixed with $10 \%$ formaldehyde for 20 min. After washing with isopropanol for $5 \mathrm{~min}$, the fixed cells were incubated with Oil Red 0 solution for $30 \mathrm{~min}$. The images were collected at three points in the field by a digital microscope (BA400Digital, China). Subsequently, Oil Red $O$ was eluted with $100 \%$ isopropanol and quantified by a microplate reader (Thermo Fisher Scientific) at $510 \mathrm{~nm}$.

\section{Western blot}

Cells were collected and proteins were extracted and the concentration was evluated by a bicinchoninic acid (BCA) protein assay kit (BestBio, Shanghai, China). Then, proteins were subjected to SDS 
polyacrylamide gel electrophoresis (SDS-PAGE) and transferred to polyvinylidene fluoride (PDVF) membranes. The PVDF membrane was incubated at room temperature with $5 \%$ defatted milk powder for $1 \mathrm{~h}$ and incubated overnight at $4 \circ \mathrm{C}$, with primary antibodies specific for anti-CDK2 (Abcam), anti-Bcl-2

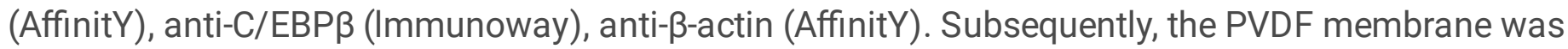
washed three times with washing buffer and incubated with HRP-labeled secondary antibody (Santa Cruz Biotechnology Inc., Heidelberg, Germany) for $1 \mathrm{~h}$ at room temperature. Finally, results were observed using the chemiluminescence (ECL) system (Beyotime, Shanghai, China) and was analyzed by ImageJ software (National Health Institute, Bethesda, MD, USA).

\section{Statistical analysis}

All statistical analyses were performed with SPSS 17.0 (SPSS Inc., Chicago, IL, USA). Data were presented as least square mean \pm standard error of the mean (SEM) based on at least three replicates for each treatment. ${ }^{*} P<0.05 ; * \star P<0.01$.

\section{Results}

\section{IMF content and serum lipid parameters}

The amount of IMF was estimated by Oil Red $O$ staining the neutral lipids in breast muscle with the aim to visualize the differences in IMF deposition of male and female chickens. Our results revealed that the density and size of lipid droplets in the female chicken group were higher as compared to those of the male chicken group. The IMF content reflected a sex-dependent pattern with significantly higher levels in 150-day female chickens $(P<0.05)$ (Fig. 1A). Besides, the estimated serum lipid parameters (TG, TC, HDL-C, LDL-C, and VLDL-C) highlighted significantly higher serum TG, LDL-C, and VLDL-C $(P<0.05)$, whereas significantly lower HDL-C $(P<0.01)$ in the female chickens than the male chickens (Fig. 1B, D, E, $F, G$ ). However, there was no statistical difference in TC between 150-day males and females (Fig. 1C).

\section{Differentially expressed genes analysis}

RNA-Seq experiment derived overall $83.14 \mathrm{~Gb}$ clean data and 597.82 million reads. Aligned with the reference genome, the mapping frequencies were found to vary from $82.38 \%$ to $93.53 \%$ for each sample. Among the mapped reads, an average of $82.66 \%$ of the total mapped reads was mapped to exons, $7.38 \%$ mapped to introns, and $9.96 \%$ mapped to the intergenic regions.

The DESeq2 program detected a total of 1281 transcripts as DEGs in the breast muscle tissue between male chickens and female chickens, of which 219 transcripts were upregulated, and 1062 transcripts were down-regulated in female chickens (Fig. 2A). In the liver tissue, a total of 598 DEGs were identified, of which 360 transcripts were upregulated and the remaining 238 transcripts were down-regulated in female chickens (Fig. 2B). The lipid metabolism-related DEGs in the breast muscle and liver were summarized in Table S1 and Table S2, respectively. Among the male and female chickens, 58 DEGs were common in the breast muscle and liver. Among these common DEGs, 10 genes, including ETNK2, PLIN2, 
OSBPL10, MFSD2A, SLC51B, GCNT2, ALDH7A1, CPT1A, LSS, and MSMO1, were relevant for lipid transport and metabolism. Among the DEGs, lipid biosynthetic process and lipid storage-related genes in pectoralis muscle tissue include ACSL1, MSMO1, HACD4, SLC27A1, LSS, LPIN1, DGAT2, and APOB that were upregulated in female chickens, indicating a significant role in lipid deposition of female chickens. As compared to the male chicken group, the expression of PLCZ1, LPIN2, and DDHD2, associated with lipid or fatty acid catabolic process, was significantly lower in the female chickens. Moreover, significant down-regulation of NR4A3 and PPARA, which participate in positive regulation of fatty acid oxidation, was witnessed in female chickens. Furthermore, some genes involved in long-chain fatty acid transport (THBS1, PLIN2), phospholipid transport (PLTP, MFSD2A, OSBPL5), cholesterol transport (LIPG, ABCA1), were significantly down-regulated in female chickens. These findings suggested the probable association of these genes with the higher IMF content in the female chickens compared with that in the male chickens. In terms of DEGs in the liver, up-regulation was evident in the genes belonging to the PPAR signaling pathway, such as $A C O X 1, A C O X 3, A C A A 1, C P T 1 A, F A B P 1$, and $F A B P 3$, in the female chickens. Additionally, significantly higher expression of the fatty acid biosynthetic process-related genes, including $H A D H A$, ELOVL2, $A B H D 2, A B H D 3, A B D H 6$, and $A B C D 3$, was observed than that in the female chicken group. However, the female chicken group manifested down-regulation of the genes involved in the steroid biosynthetic process (DHCR24, SQLE, NSDHL, CYP51A1, LSS, MVD, CYP17A1, HSD17B7, DHCR7, MSMO1). KEGG pathway analysis of the DEGs

The significantly enriched pathways obtained from the KEGG pathway analysis, conducted based on the known DEGs, are illustrated in Fig. 3. We identified 238 DEGs annotated into 174 pathways in FBM vs. MBM (Fig. 3A) and 197 DEGs annotated into 160 pathways in FL vs. ML (Fig. 3B). Since the homeostasis between synthesis, transport, and degradation of lipids regulates the IMF content (Zhang et al. 2017), we focused mainly on the pathways directly involved in lipid metabolism. The breast muscle and liver of female and male chickens witnessed five common significantly enriched pathways (metabolic pathways, fatty acid degradation, fatty acid biosynthesis, glycolysis/gluconeogenesis, and PPAR signaling pathway) $(P<0.05)$. Moreover, the DEGs in the liver tissue were also found to be significantly enriched in steroid biosynthesis, steroid hormone biosynthesis, fatty acid metabolism, citrate cycle, and five amino acid-related metabolism pathways $(P<0.05)$.

\subsection{Gene expression validation of DEGs by qRT-PCR}

The results of the RNA-Seq analysis were further confirmed by validating the expression data of randomly selected ten DEGs. Results revealed expression of five DEGs (APOB, SLC27A1, DGAT2, PLTP, LIPG) in the muscle, whereas five DEGs (CPT1A, ACAA1, FABP3, DHCR24, MSMO1) were expressed in the liver. Consistency of the qRT-PCR result with the RNA-Seq data with a correlation coefficient of 0.986 authenticated the accuracy of RNA-Seq (Fig. 4).

\subsection{PLIN2 promoted intramuscular preadipocyte proliferation, differentiation, and inhibited apoptosis}

PLIN2, a common DSG in the breast muscle and liver, was studied to further explore the biological significance of candidate genes. The tissue expression patterns of PLIN2 were determined by analyzing 
13 tissues of female chickens using qRT-PCR. High expression of PLIN2 in the liver, subcutaneous fat, and abdominal fat indicated its potential role in the lipid metabolism of chicken (Fig. 5). Transfection with siRNA knocked down the PLIN2 expression, which helped to elucidate the regulatory role of PLIN2 in chicken intramuscular preadipocyte proliferation, apoptosis and differentiation. Compared with the negative control (NC) group, transfection with siRNA significantly downregulated the mRNA expression level of PLIN2 (Fig. 6A).

To explore the role of PLIN2 on chicken intramuscular preadipocyte proliferation, we detected the mRNA expression of cell-proliferation-related genes, including Cyclin D1 (CCND1), Cyclin D2 (CCND2), cyclin dependent kinase 2(CDK2), proliferating cell nuclear antigen ( $P C N A)$ and a marker of proliferation Ki-67 (Ki67). Results showed that the mRNA expression levels of CCND1, CCND2, CDK2, PCNA and Ki67 were all significantly decreased after transfected with si-PLIN2, compared with the negative control (NC) group (Fig. 6B). The protein expression level of $C D K 2$ was also detected by western blotting and the result was consistent with the qRT-PCR results (Fig. 6C). Furthermore, CCK-8 results showed that the cell vitality of the si-PLIN2 transfected group was significantly lower than that of the NC group after 12, 24, 36, and 48h of transfection (Fig. 6D). EdU assay results showed that the percentage of EdU positive cells were significantly reduced in si-PLIN2 transfected group (Fig. 6E and F).

To investigated the role of $P L I N 2$ in chicken intramuscular preadipocyte differentiation, we examined the mRNA expression levels of the adipogenic transcripts PPARY, FABP4,C/EBPa and C/EBP 3 . Results showed that mRNA expression levels of these genes were all downregulated after transfected with siPLIN2 (Fig. 7A). The protein expression level of $C / E B P \beta$ was consistent with the qRT-PCR results (Fig. 7B). Besides, oil red $O$ staining corroborated a decrease in the number of intracellular lipid droplets in the siRNA-PLIN2 group (Fig. $7 \mathrm{C}$ ), and the $\mathrm{OD}_{510}$ values of the siRNA-PLIN2 group were also significantly lower as compared to that of the NC group (Fig. 7D). Cumulatively, these results indicated PLIN2 promoted intramuscular preadipocyte proliferation, differentiation, and inhibited apoptosis.

To further investigated whether PLIN2 could also modulate preadipocyte apoptosis, the mRNA expression levels of crucial mediators of apoptosis, including caspase-3, caspase-8 and BCl-2 were examined. We found the mRNA expression levels of caspase-3, caspase-8, caspase-9 were upregulated and Bcl-2 mRNA and protein expression levels were downregulated after transfected with si-PLIN2 (Fig. 8A and B). The Apoptosis and Necrosis Assay results suggested that the interfere with PLIN2 significantly increased preadipocyte apoptosis when compared with the NC group (Fig. 8C and D).

\section{Discussion}

IMF content is predominant among the several factors affecting meat quality. IMF deposition is influenced by an important factor- gender, and it is generally witnessed that the content was higher in female chicken than that of male chicken (Guo-Bin et al. 2010; Yang et al. 2015). In accordance with previous studies, the results of the present study also demonstrated a sex-dependent significantly higher IMF content in 150-day female Daheng broilers than male chickens. The equilibrium between lipid 
synthesis, transport, uptake, and catabolism determines the lipid deposition (Yan et al. 2015). In mammals, adipocytes are the major site for de novo synthesis of fatty acids, whereas, in the case of chicken, lipid biosynthesis mainly takes place in the liver (Leveille et al. 1975). After being synthesized in the liver, fatty acids are exported to muscle and adipose tissue by the peripheral vascular system (Zhuo et al. 2015). Thus, chicken IMF accumulation depends on the transport and uptake of blood lipids as well as subsequent lipogenesis in the muscle (Wang et al. 2012). Serum lipid parameters (TG, TC, HDL-C, LDL-C, and VLDL-C) were estimated between 150-day female chickens and male chickens. According to Dominique et al., a two-fold higher plasma concentration of VLDL was evident in the fat chicken line than in the lean chicken line (Dominique et al.). It is documented that serum VLDL can be considered as an indirect indicator for fat deposition (Hermier 1997). Moreover, the fat deposition rate was also significantly correlated with the serum TG concentration, and greater TG concentration was always associated with higher IMF in the breast muscle of chickens (Chen et al. 2017). The present study revealed significantly higher contents of VLDL and TG concentration in the female chicken as compared to that of the male chicken, which signified an augmented circulating lipid flux. Homeostasis between de novo synthesis, dietary intake, and metabolism is reflected by the total body cholesterol (TC) pool (Griffin and Lichtenstein 2013). LDL and HDL are responsible for cholesterol transport in the blood. Blood cholesterol is delivered throughout the body by LDL-C, and HDL-C could recycle cholesterol from the body tissues back to the liver, which turns it into bile and excretes it through the gastrointestinal tract (P.O. et al. 2016). Therefore, it is rational to infer that higher LDL-C concentration and lower HDL-C concentration in the female chickens could affect increased lipid deposition in pectoralis muscle tissue.

The key role played by IMF content in multiple quality traits establishes it as an important index for superior-quality chicken breeding (Ye et al. 2014). To elucidate the molecular regulation of IMF deposition, the expression profile of breast muscle and liver between female and male chickens was investigated. In poultry, lipid synthesis predominates in the liver, and the IMF content primarily relies on the net balance among lipid synthesis, transport, uptake, and catabolism (Yan et al. 2015). Numerous key genes and metabolic pathways are involved in these processes. The differential deposition mechanism of IMF in different breeds and ages has been addressed in previous studies (Liu et al. 2017; Zhang et al. 2018). The present study screened the DEGs associated with lipid metabolism in breast muscle and liver between female chicken and male chickens, with the goal to unearth the molecular mechanisms affecting IMF in different genders.

Previous studies have documented the liver as the site for more than $70 \%$ of the de novo synthesis of fatty acids for poultry and the critical role it plays in lipid synthesis, degradation, and transport (Leveille et al. 1968). These findings motivated the scientists to comprehend the genetic difference in hepatic lipid metabolism (Li et al. 2016; Li et al. 2015). Fatty acid-binding proteins (FABPs) have attracted interest from many researchers owing to their diverse biological functions, including fatty acid oxidation (Gan et al. 2015), transport (Storch and Thumser 2000), and lipid storage (He et al. 2013). FABP1, FABP3, and FABP4 were widely reported as vital candidate genes for IMF deposition in chicken (Gao et al. 2015; Li et al. 2015). According to $L i$ et al., the liver of laying hens manifested over-expression of FABP1 and FABP3 levels compared to the juvenile hens to meet the requirement of laying eggs ( $\mathrm{Li}$ et al. 2015). This was in 
agreement with the findings of the present study that also revealed significant up-regulation of both $F A B P 1$ and $F A B P 3$ in the liver of female chickens compared with male chickens, thereby signifying their role in promoting lipid metabolism in the PPAR signaling pathway in female chickens. Meanwhile, overexpression was also noted for $A P O B$, another lipid transport-related gene, in female chickens than in male chickens (Lee et al. 1996). The female chicken group also witnessed up-regulation of some fatty acid biosynthesis-related genes, including ELOVL2 (Morais et al. 2009), HSD3B1 (Lavoie and King 2009). Furthermore, among all the significant DEGs in breast muscle tissue, several functional genes have been recognized as candidate genes for IMF, such as ACSL 1 (Widmann et al. 2011), DGAT2 (Cui et al. 2011), and CPT1A (Qiu et al. 2017).

The present study confirmed the involvement of a number of potential genes affecting IMF. However, their molecular mechanisms are still ambiguous. Here, we selected a common DEG in breast muscle and liver to explore the molecular mechanism in IMF deposition. At the cellular level, variability in IMF content is fundamentally correlated to the number and size of intramuscular adipocytes, differentiated by intramuscular preadipocytes (Hocquette et al. 2010). The present study tried to ascertain the role of PLIN2 in the process of intramuscular preadipocyte proliferation, differentiation, and apoptosis. Perilipins 2 (PLIN2), a member of the perilipin family, is a major group of lipid droplets-associated proteins with both structural and regulatory functions (Brasaemle 2007). Research has documented the role of PLIN2 in lipid droplet accumulation in other species (Bildirici et al. 2018; Tsai et al. 2017; Dahlhoff et al. 2013), while the effect of the PLIN2 gene on lipid metabolism in chicken preadipocytes is rarely reported. In the present study, knockdown of $P L I N 2$ significantly inhibited the expression of proliferation-related genes (CCND1, CCND2, CDK2, PCNA and Ki67) and inhibited the cell vitality and reduced the proliferating cells ratio. These results suggested that $P L I N 2$ could promote chicken intramuscular preadipocyte proliferation by regulating factors involved in the control of cell proliferation.

During the process of precursor adipocytes differentiated into mature fat cells, lipid droplets gradually formed and get larger (Li and Raza 2020). Adipogenic differentiation related marker genes include PPARY, FABP4, C/EBPa and C/EBP $\beta$ (Li and Raza 2020). After interfere of PLIN2, the expression of these key genes all decreased. Studies have shown a key role for $C / E B P \beta$ in regulating adipocytes differentiated (Raciti et al. 2018). Here, C/EBP $\beta$ protein expression level also decreased in si-PLIN2 group. Besides, a decreased lipid accumulation in the si-PLIN2 group was also highlighted from the Oil Red 0 staining results. These results suggest that $P L I N 2$ could promote chicken intramuscular preadipocyte differentiation.

Caspase-3 and caspase-8 are crucial mediators of apoptosis (Porter and Jänicke 1999; Kruidering and Evan 2000; Würstle et al. 2012). Expectantly, caspase-3 and caspase-8 expressions increased in intramuscular preadipocytes transfected with the si-PLIN2, strongly suggesting that PLIN2 inhibits apoptosis in intramuscular preadipocytes. $B c /-2$, a central player in the genetic program of eukaryotic cells that favors survival and inhibits apoptosis, can block p53-dependent apoptosis (Chiou et al. 1994). Using qRT-PCR and western blot, we found that PLIN2 promoted BCl-2 mRNA and protein expression in chicken intramuscular preadipocytes. Besides, the interfere with PLIN2 significantly increased 
preadipocyte apoptosis when compared with the NC. These results suggest that PLIN2 could inhibit chicken intramuscular preadipocyte apoptosis.

\section{Conclusion}

Findings from this study concluded significantly higher IMF content of 150-day female chickens in comparison to that of male chickens. The female chickens also demonstrated higher serum TG, LDL-C, and VLDL, and significantly lower HDL-C than male chickens. Furthermore, DEGs involved in lipid metabolism in muscle and liver were identified between female chicken and male chickens, which could partially interpret possible reasons for the differences in IMF content. Cellular results indicates that PLIN2 could promote chicken IMF deposition by promoting intramuscular preadipocyte proliferation, differentiation, and inhibiting apoptosis. Therefore, PLIN2 may be considered as a molecular marker for poultry meat quality and applying this gene in early breed selection.

\section{Declarations}

\section{Data availability}

The raw data supporting the conclusions of this article will be made available by the authors, without undue reservation. All the data are available in the SRA database with accession number PRJNA732829.

\section{Author Contributions}

Conceptualization, J.L. and C.Y.; methodology, J.L. and P.R.; software, J.L. and Z.L.; investigation, J.L., C.Y., D.Z. and L.W.; resources, C.Y. and X.J.; writing-original draft preparation, J.L.; writing-review and editing, C.Y., X.J., P.R. and Y.L.; supervision, X.J. and Y.L.; project administration, Y.L.; funding acquisition, Y.L. and C.Y. All authors have read and agreed to the published version of the manuscript.

\section{Ethics Statement}

The animal study was reviewed and approved by the Ethics Committee for Animal Experiments of Sichuan agricultural university.

\section{Funding}

This research was funded by Sichuan Science and Technology Program (Grant NO. 2021YFYZ0031), the Innovation Key Laboratory of Sichuan Province (Grant NO. 2017JZ0033) and Key Technology Support Program of Sichuan Province (Grant NO. 2018NZDZX0004).

\section{Competing interests}

The authors declare that the research was conducted in the absence of any commercial or financial relationships that could be construed as a potential conflict of interest. 


\section{Data Availability Statement}

The raw data supporting the conclusions of this article will be made available by the authors, without undue reservation. All the data are available in the SRA database with accession number PRJNA732829.

\section{References}

1. Bildirici I, Schaiff WT, Chen B, Morizane M, Oh SY, O'Brien M, Sonnenberg-Hirche C, Chu T, Barak Y, Nelson DM, Sadovsky Y (2018) PLIN2 Is Essential for Trophoblastic Lipid Droplet Accumulation and Cell Survival During Hypoxia. Endocrinology 159 (12):3937-3949. doi:10.1210/en.2018-00752

2. Brasaemle DL (2007) Thematic review series: adipocyte biology. The perilipin family of structural lipid droplet proteins: stabilization of lipid droplets and control of lipolysis. J Lipid Res 48 (12):25472559. doi:10.1194/jlr.R700014-JLR200

3. Chen, Xingyong, Geng, Zhaoyu, Niu, Juanjuan (2017) Gene expression and plasma lipid content in relation to intramuscular fat in Chinese indigenous Wuhua chicken. Journal of Applied Poultry Research

4. Chiou SK, Rao L, White E (1994) Bcl-2 blocks p53-dependent apoptosis. Molecular and cellular biology 14 (4):2556-2563. doi:10.1128/mcb.14.4.2556

5. Cui H, Zhao G, Liu R, Zheng M, Chen J, Wen J (2012a) FSH stimulates lipid biosynthesis in chicken adipose tissue by upregulating the expression of its receptor FSHR. Journal of Lipid Research 53 (5):909-917

6. Cui HX, Liu RR, Zhao GP, Zheng MQ, Chen JL, Wen J (2012b) Identification of differentially expressed genes and pathways for intramuscular fat deposition in pectoralis major tissues of fast-and slowgrowing chickens. BMC Genomics 13:213. doi:10.1186/1471-2164-13-213

7. Cui JX, Zeng YQ, Wang H, Chen W, Du JF, Chen QM, Hu YX, Yang L (2011) The effects of DGAT1 and DGAT2 mRNA expression on fat deposition in fatty and lean breeds of pig. Livestock Science 140 (13):292-296

8. Dahlhoff M, Camera E, Picardo M, Zouboulis CC, Chan L, Chang BH, Schneider MR (2013) PLIN2, the major perilipin regulated during sebocyte differentiation, controls sebaceous lipid accumulation in vitro and sebaceous gland size in vivo. Biochim Biophys Acta 1830 (10):4642-4649. doi:10.1016/j.bbagen.2013.05.016

9. Dennis G, Jr., Sherman BT, Hosack DA, Yang J, Gao W, Lane HC, Lempicki RA (2003) DAVID: Database for Annotation, Visualization, and Integrated Discovery. Genome biology 4 (5):P3

10. Dominique $\mathrm{H}$, John CM, Bernard L Plasma lipoprotein profile in fasted and refed chickens of two strains selected for high or low adiposity. Journal of Nutrition (6):1112-1121

11. Gan L, Liu Z, Cao W, Zhang Z, Sun C (2015) FABP4 reversed the regulation of leptin on mitochondrial fatty acid oxidation in mice adipocytes. Sci Rep 5:13588. doi:10.1038/srep13588

12. Gao GL, Na W, Wang YX, Zhang HF, Li H, Wang QG (2015) Role of a liver fatty acid-binding protein gene in lipid metabolism in chicken hepatocytes. Genetics and molecular research : GMR 14 
(2):4847-4857. doi:10.4238/2015.May.11.17

13. Gawrieh S (2015) Sex Hormones, Sex Hormone-Binding Globulin, and Liver Fat: Which Came First, the Chicken or the Egg? Clinical gastroenterology and hepatology : the official clinical practice journal of the American Gastroenterological Association 13 (9):1694-1696.

doi:10.1016/j.cgh.2015.04.182

14. Griffin JD, Lichtenstein AH (2013) Dietary Cholesterol and Plasma Lipoprotein Profiles: RandomizedControlled Trials. Current nutrition reports 2 (4):274-282. doi:10.1007/s13668-013-0064-0

15. Guo-Bin C, Li-Li L, Xue-Yu Z, Ke-Hua W, Guo-Hong C (2010) Development Rule of Intramuscular Fat Content in Chicken. Journal of Animal and Veterinary Advances 9 (2):297-298

16. He J, Tian Y, Li J, Shen J, Tao Z, Fu Y, Niu D, Lu L (2013) Expression pattern of L-FABP gene in different tissues and its regulation of fat metabolism-related genes in duck. Mol Biol Rep 40 (1):189195. doi:10.1007/s11033-012-2048-3

17. Hermier D (1997) Lipoprotein metabolism and fattening in poultry. The Journal of nutrition 127 (5 Suppl):805s-808s. doi:10.1093/jn/127.5.805S

18. Hocquette JF, Gondret F, Baéza E, Médale F, Jurie C, Pethick DW (2010) Intramuscular fat content in meat-producing animals: development, genetic and nutritional control, and identification of putative markers. Animal 4 (2):303-319. doi:10.1017/s1751731109991091

19. Jeong J, Bong J, Kim GD, Joo ST, Lee HJ, Baik M (2013) Transcriptome changes favoring intramuscular fat deposition in the longissimus muscle following castration of bulls. J Anim Sci 91 (10):4692-4704. doi:10.2527/jas.2012-6089

20. Kruidering M, Evan GI (2000) Caspase-8 in apoptosis: the beginning of "the end"? IUBMB life 50 (2):85-90. doi:10.1080/713803693

21. Lavoie HA, King SR (2009) Transcriptional regulation of steroidogenic genes: STARD1, CYP11A1 and HSD3B. Experimental biology and medicine (Maywood, NJ) 234 (8):880-907. doi:10.3181/0903-mr97

22. Lee SY, Nagy BP, Brooks AR, Wang DM, Paulweber B, Levy-Wilson B (1996) Members of the caudal family of homeodomain proteins repress transcription from the human apolipoprotein $B$ promoter in intestinal cells. The Journal of biological chemistry 271 (2):707-718. doi:10.1074/jbc.271.2.707

23. Leveille GA, O'Hea EK, Chakbabarty K (1968) In vivo lipogenesis in the domestic chicken.

Proceedings of the Society for Experimental Biology and Medicine Society for Experimental Biology and Medicine (New York, NY) 128 (2):398-401. doi:10.3181/00379727-128-33022

24. Leveille GA, Romsos DR, Yeh Y, O'Hea EK (1975) Lipid biosynthesis in the chick. A consideration of site of synthesis, influence of diet and possible regulatory mechanisms. Poultry science 54 (4):10751093. doi:10.3382/ps.0541075

25. Li H, Ma Z, Jia L, Li Y, Xu C, Wang T, Han R, Jiang R, Li Z, Sun G, Kang X, Liu X (2016) Systematic analysis of the regulatory functions of microRNAs in chicken hepatic lipid metabolism. Sci Rep 6:31766. doi:10.1038/srep31766 
26. Li H, Wang T, Xu C, Wang D, Ren J, Li Y, Tian Y, Wang Y, Jiao Y, Kang X, Liu X (2015) Transcriptome profile of liver at different physiological stages reveals potential mode for lipid metabolism in laying hens. BMC Genomics 16:763. doi:10.1186/s12864-015-1943-0

27. Li J, Yang C, Peng H, Yin H, Wang Y, Hu Y, Yu C, Jiang X, Du H, Li Q, Liu Y (2019) Effects of Slaughter Age on Muscle Characteristics and Meat Quality Traits of Da-Heng Meat Type Birds. Animals : an open access journal from MDPI 10 (1). doi:10.3390/ani10010069

28. Li S, Raza SHA (2020) Overexpression of PLIN1 Promotes Lipid Metabolism in Bovine Adipocytes. 10 (11). doi:10.3390/ani10111944

29. Liu L, Cui H, Fu R, Zheng M, Liu R, Zhao G, Wen J (2017) The regulation of IMF deposition in pectoralis major of fast- and slow- growing chickens at hatching. 8:77. doi:10.1186/s40104-0170207-z

30. Liu L, Liu X, Cui H, Liu R, Zhao G, Wen J (2019) Transcriptional insights into key genes and pathways controlling muscle lipid metabolism in broiler chickens. 20 (1):863. doi:10.1186/s12864-019-6221-0

31. Miao X, Luo Q, Qin X, Guo Y, Zhao H (2015) Genome-wide mRNA-seq profiling reveals predominant down-regulation of lipid metabolic processes in adipose tissues of Small Tail Han than Dorset sheep. Biochemical and biophysical research communications 467 (2):413-420. doi:10.1016/j.bbrc.2015.09.129

32. Morais S, Monroig O, Zheng X, Leaver MJ, Tocher DR (2009) Highly unsaturated fatty acid synthesis in Atlantic salmon: characterization of ELOVL5- and ELOVL2-like elongases. Marine biotechnology (New York, NY) 11 (5):627-639. doi:10.1007/s10126-009-9179-0

33. P.O. A, V.A. O, E.O. F (2016) Comparative Evaluation of Cholesterol Content and Storage Quality of Chicken and Quail Eggs. World Journal of Nutrition and Health 4 (1):5-9

34. Petracci M, Cavani C (2012) Muscle growth and poultry meat quality issues. Nutrients 4 (1):1-12. doi:10.3390/nu4010001

35. Petracci M, Mudalal S, Soglia F, Cavani C (2015) Meat quality in fast-growing broiler chickens. Worlds Poultry Science Journal 71 (2):363-374

36. Porter AG, Jänicke RU (1999) Emerging roles of caspase-3 in apoptosis. Cell death and differentiation 6 (2):99-104. doi:10.1038/sj.cdd.4400476

37. Qiu F, Xie L, Ma JE, Luo W, Zhang L, Chao Z, Chen S, Nie Q, Lin Z, Zhang X (2017) Lower Expression of SLC27A1 Enhances Intramuscular Fat Deposition in Chicken via Down-Regulated Fatty Acid Oxidation Mediated by CPT1A. Frontiers in physiology 8:449. doi:10.3389/fphys.2017.00449

38. Raciti GA, Fiory F, Campitelli M, Desiderio A, Spinelli R, Longo M, Nigro C, Pepe G, Sommella E, Campiglia P, Formisano P, Beguinot F, Miele C (2018) Citrus aurantium L. dry extracts promote $\mathrm{C} / \mathrm{ebp} \beta$ expression and improve adipocyte differentiation in 3T3-L1 cells. PLoS One 13 (3):e0193704. doi:10.1371/journal.pone.0193704

39. Ramayo-Caldas Y, Mach N, Esteve-Codina A, Corominas J, Castelló A, Ballester M, Estellé J, lbáñezEscriche N, Fernández Al, Pérez-Enciso M, Folch JM (2012) Liver transcriptome profile in pigs with 
extreme phenotypes of intramuscular fatty acid composition. BMC Genomics 13:547. doi:10.1186/1471-2164-13-547

40. Royan M, Navidshad B (2016) Peroxisome proliferator-activated receptor gamma (PPARy), a key regulatory gene of lipid metabolism in chicken. Worlds Poultry Science Journal 72 (04):773-784

41. Saez G, Davail S, Gentès G, Hocquette JF, Jourdan T, Degrace P, Baéza E (2009) Gene expression and protein content in relation to intramuscular fat content in Muscovy and Pekin ducks. Poultry science 88 (11):2382-2391. doi:10.3382/ps.2009-00208

42. Shi H, Wang Q, Wang Y, Leng L, Zhang Q, Shang Z, Li H (2010) Adipocyte fatty acid-binding protein: an important gene related to lipid metabolism in chicken adipocytes. Comparative biochemistry and physiology Part B, Biochemistry \& molecular biology 157 (4):357-363. doi:10.1016/j.cbpb.2010.08.005

43. Storch J, Thumser AE (2000) The fatty acid transport function of fatty acid-binding proteins. Biochim Biophys Acta 1486 (1):28-44. doi:10.1016/s1388-1981(00)00046-9

44. Tsai TH, Chen E, Li L, Saha P, Lee HJ, Huang LS, Shelness GS, Chan L, Chang BH (2017) The constitutive lipid droplet protein PLIN2 regulates autophagy in liver. Autophagy 13 (7):1130-1144. doi:10.1080/15548627.2017.1319544

45. Würstle ML, Laussmann MA, Rehm M (2012) The central role of initiator caspase-9 in apoptosis signal transduction and the regulation of its activation and activity on the apoptosome. Experimental cell research 318 (11):1213-1220. doi:10.1016/j.yexcr.2012.02.013

46. Wang X, Wei D, Song Z, Jiao H, Lin H (2012) Effects of fatty acid treatments on the dexamethasoneinduced intramuscular lipid accumulation in chickens. PLoS One 7 (5):e36663. doi:10.1371/journal.pone.0036663

47. Wang Y, Ghaffari N, Johnson CD, Braga-Neto UM, Wang H, Chen R, Zhou H (2011) Evaluation of the coverage and depth of transcriptome by RNA-Seq in chickens. BMC bioinformatics 12 Suppl 10 (Suppl 10):S5. doi:10.1186/1471-2105-12-s10-s5

48. Warner RD, Greenwood PL, Pethick DW, Ferguson DM (2010) Genetic and environmental effects on meat quality. Meat Sci 86 (1):171-183. doi:10.1016/j.meatsci.2010.04.042

49. Widmann P, Nuernberg K, Kuehn C, Weikard R (2011) Association of an ACSL1 gene variant with polyunsaturated fatty acids in bovine skeletal muscle. BMC Genet 12:96. doi:10.1186/1471-2156-1296

50. Yan J, Liao K, Wang T, Mai K, Xu W, Ai Q (2015) Dietary Lipid Levels Influence Lipid Deposition in the Liver of Large Yellow Croaker (Larimichthys crocea) by Regulating Lipoprotein Receptors, Fatty Acid Uptake and Triacylglycerol Synthesis and Catabolism at the Transcriptional Level. PLoS One 10 (6):e0129937. doi:10.1371/journal.pone.0129937

51. Yang Y, Wen J, Fang GY, Li ZR, Liu J (2015) The effects of raising system on the lipid metabolism and meat quality traits of slow-growing chickens. Journal of Applied Animal Research 43 (2):1-6

52. Ye M, Zhou B, Wei S, Ding M, Lu X, Shi X, Ding J, Yang S, Wei W (2016) Transcriptomic Analysis Identifies Candidate Genes Related to Intramuscular Fat Deposition and Fatty Acid Composition in 
the Breast Muscle of Squabs (Columba). G3 (Bethesda, Md) 6 (7):2081-2090.

doi:10.1534/g3.116.029793

53. Ye Y, Lin S, Mu H, Tang X, Ou Y, Chen J, Ma Y, Li Y (2014) Analysis of differentially expressed genes and signaling pathways related to intramuscular fat deposition in skeletal muscle of sex-linked dwarf chickens. BioMed research international 2014:724274. doi:10.1155/2014/724274

54. Yin L, Yu L, Zhang L, Ran J, Li J, Yang C, Jiang X, Du H, Hu X, Liu Y (2019) Transcriptome analysis reveals differentially expressed genes and pathways for oviduct development and defense in prelaying and laying hens. 82 (3):e13159. doi:10.1111/aji.13159

55. Zerehdaran S, Vereijken AL, van Arendonk JA, van der Waaijt EH (2004) Estimation of genetic parameters for fat deposition and carcass traits in broilers. Poultry science 83 (4):521-525. doi:10.1093/ps/83.4.521

56. Zhang M, Li DH, Li F, Sun JW, Jiang RR, Li ZJ, Han RL, Li GX, Liu XJ, Kang XT, Sun GR (2018) Integrated Analysis of MiRNA and Genes Associated with Meat Quality Reveals that Gga-MiR-140-5p Affects Intramuscular Fat Deposition in Chickens. Cellular physiology and biochemistry : international journal of experimental cellular physiology, biochemistry, and pharmacology 46 (6):2421-2433. doi:10.1159/000489649

57. Zhang R, Lin Y, Zhi L, Liao H, Zuo L, Li Z, Xu Y (2017) Expression profiles and associations of adiponectin and adiponectin receptors with intramuscular fat in Tibetan chicken. Br Poult Sci 58 (2):151-157. doi:10.1080/00071668.2016.1268252

58. Zhuo Z, Lamont SJ, Lee WR, Abasht B (2015) RNA-Seq Analysis of Abdominal Fat Reveals Differences between Modern Commercial Broiler Chickens with High and Low Feed Efficiencies. PLoS One 10 (8):e0135810. doi:10.1371/journal.pone.0135810

\section{Tables}

Due to technical limitations, table 1 is only available as a download in the Supplemental Files section.

\section{Supplemental Tables}

Tables S1 and S2 are not available with this version.

\section{Figures}


A

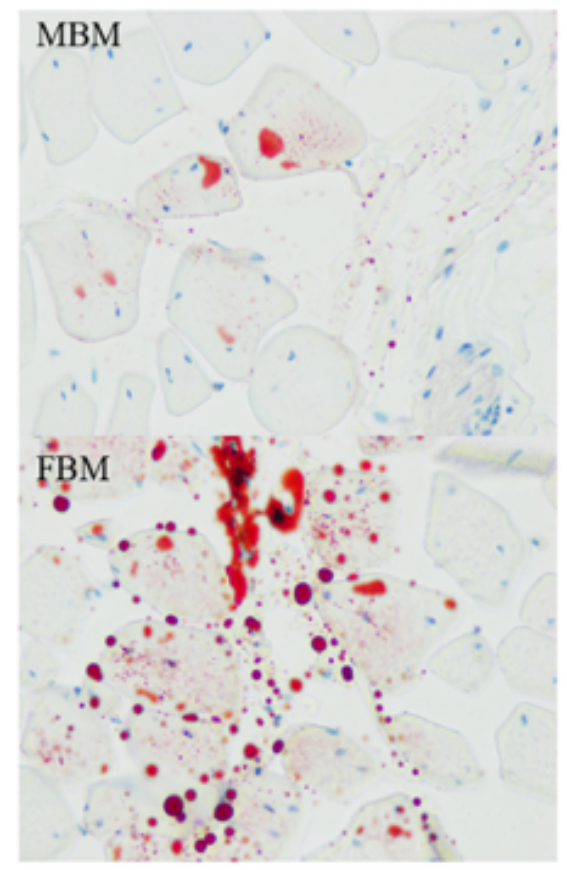

B

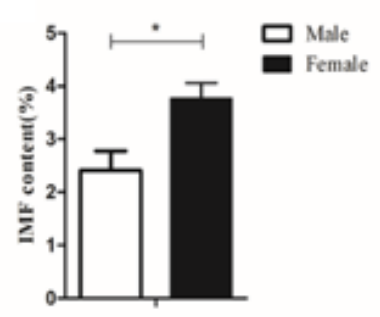

E

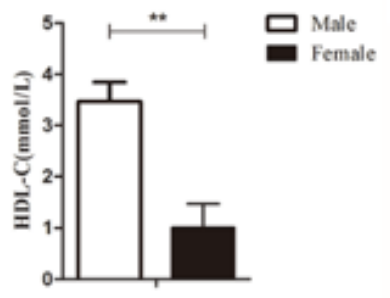

C

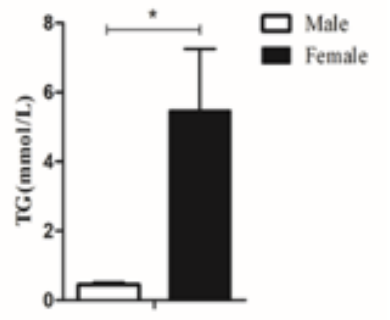

$\mathrm{F}$

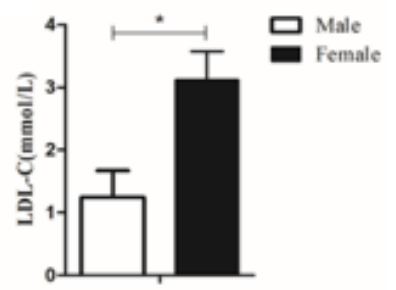

D

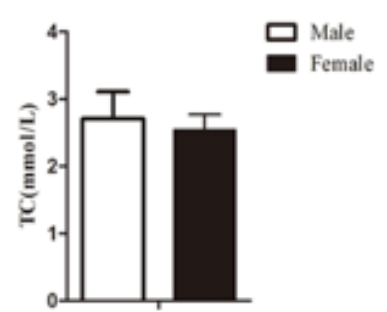

G

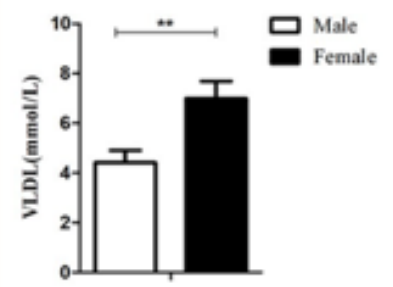

\section{Figure 1}

IMF content and serum lipid measurement. (A) Oil Red O staining for neutral lipids in breast muscle of male chicken and female chicken (400x magnification). (B) IMF content of male chicken and female chicken. (C, D, E, F, G) The levels of serum triglycerides (TG), total cholesterol (TC), high density lipoprotein $(H D L)$, low density lipoprotein (LDL) and very low density lipoprotein (VLDL) between male chicken and female chicken, respectively. ${ }^{*} \mathrm{p}<0.05 ;{ }^{*} \mathrm{p}<0.01$ 

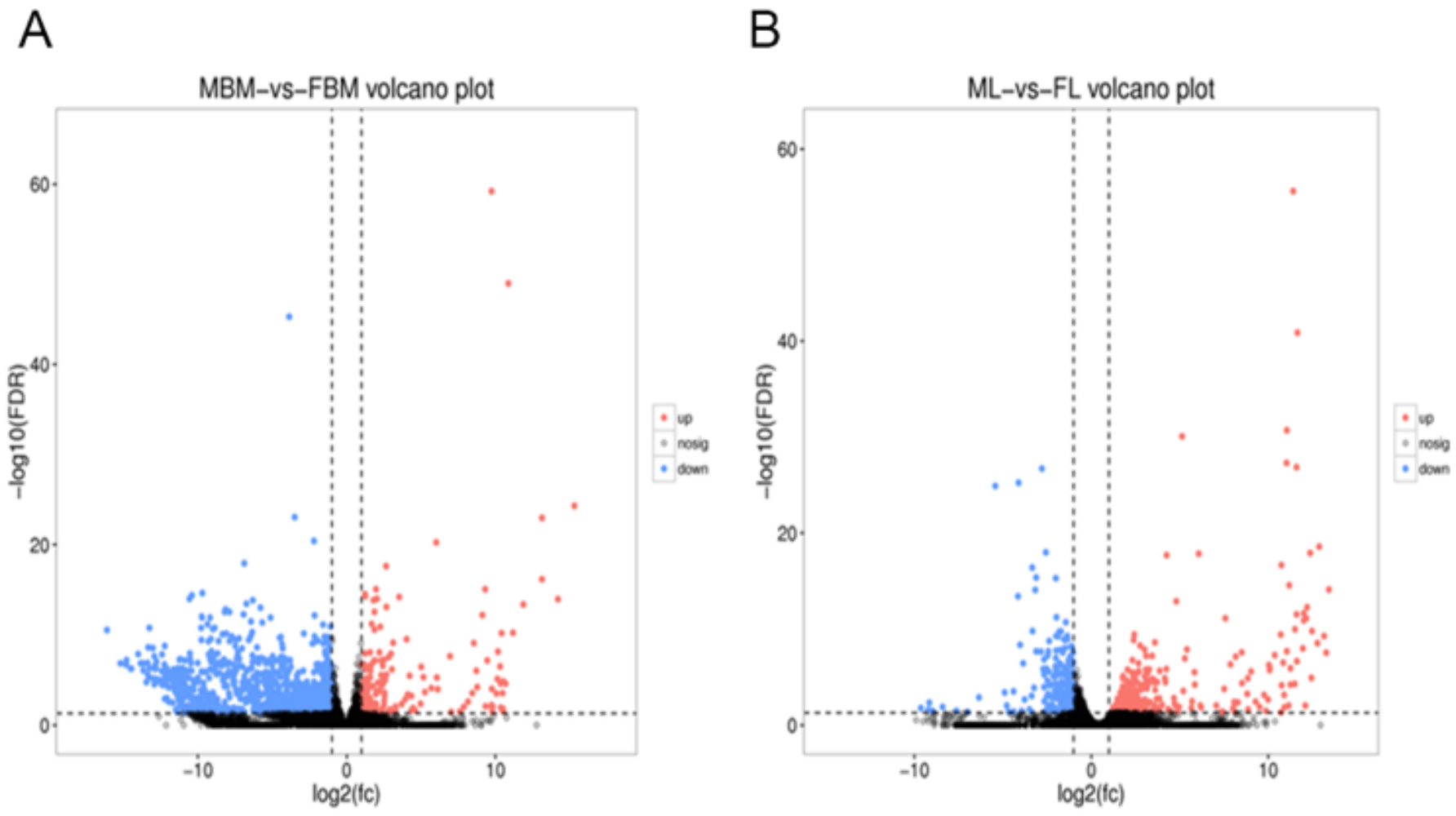

Figure 2

(A) Differentially expressed volcano diagram and up-down regulation in breast muscle of male chicken and female chicken. (B) Differentially expressed volcano diagram and up-down regulation in liver tissue of male chicken and female chicken. MBM: breast muscle of male chicken; FBM: breast muscle of female chicken; ML: liver of male chicken; FL: liver of female chicken. 
A

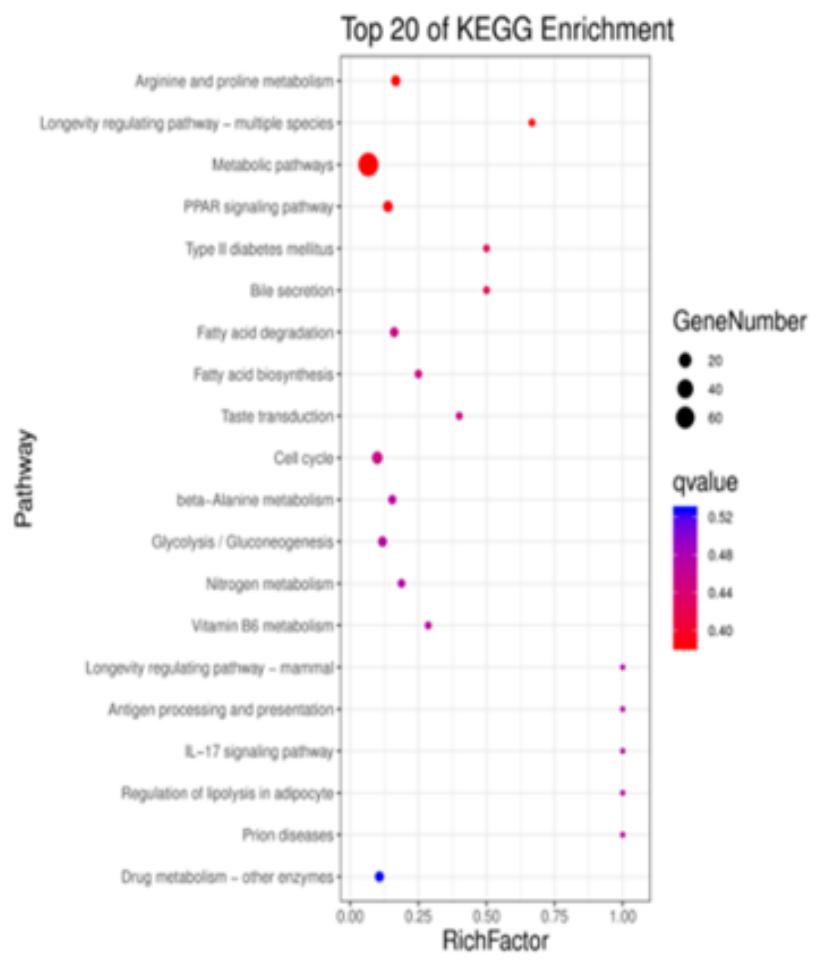

B

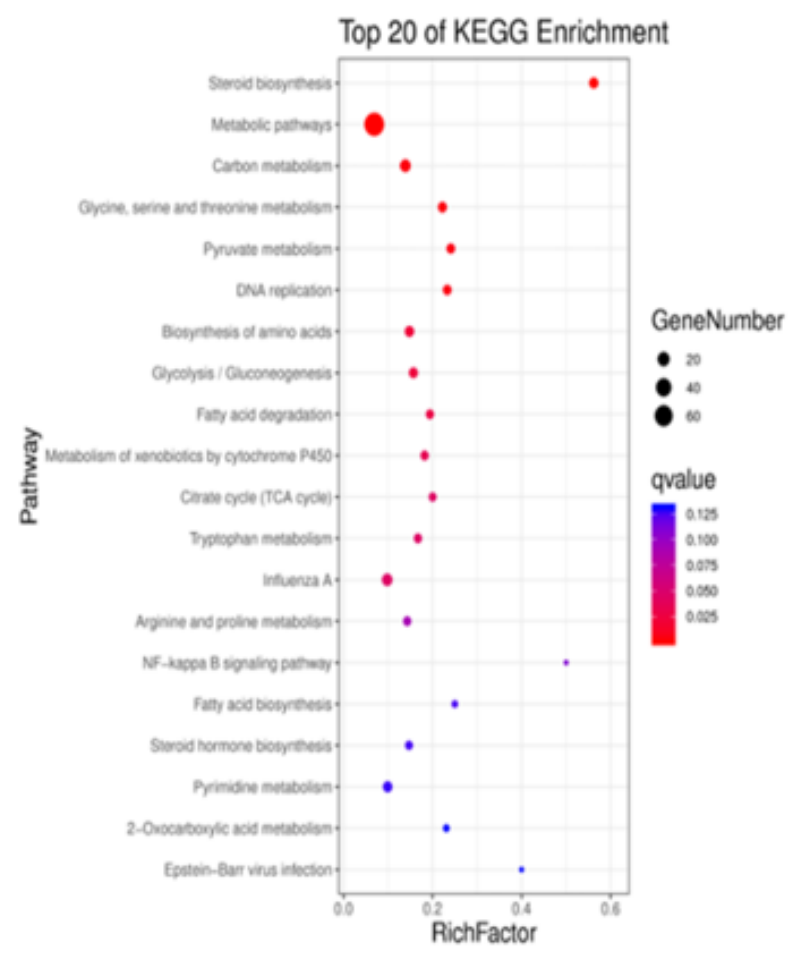

Figure 3

Top 20 significantly enriched pathways of FBM vs MBM (A) and FL vs ML (B) based on differentially expressed genes (DEGs) by KEGG pathway enrichment analysis. MBM: breast muscle of male chicken; FBM: breast muscle of female chicken; ML: liver of male chicken; FL: liver of female chicken.

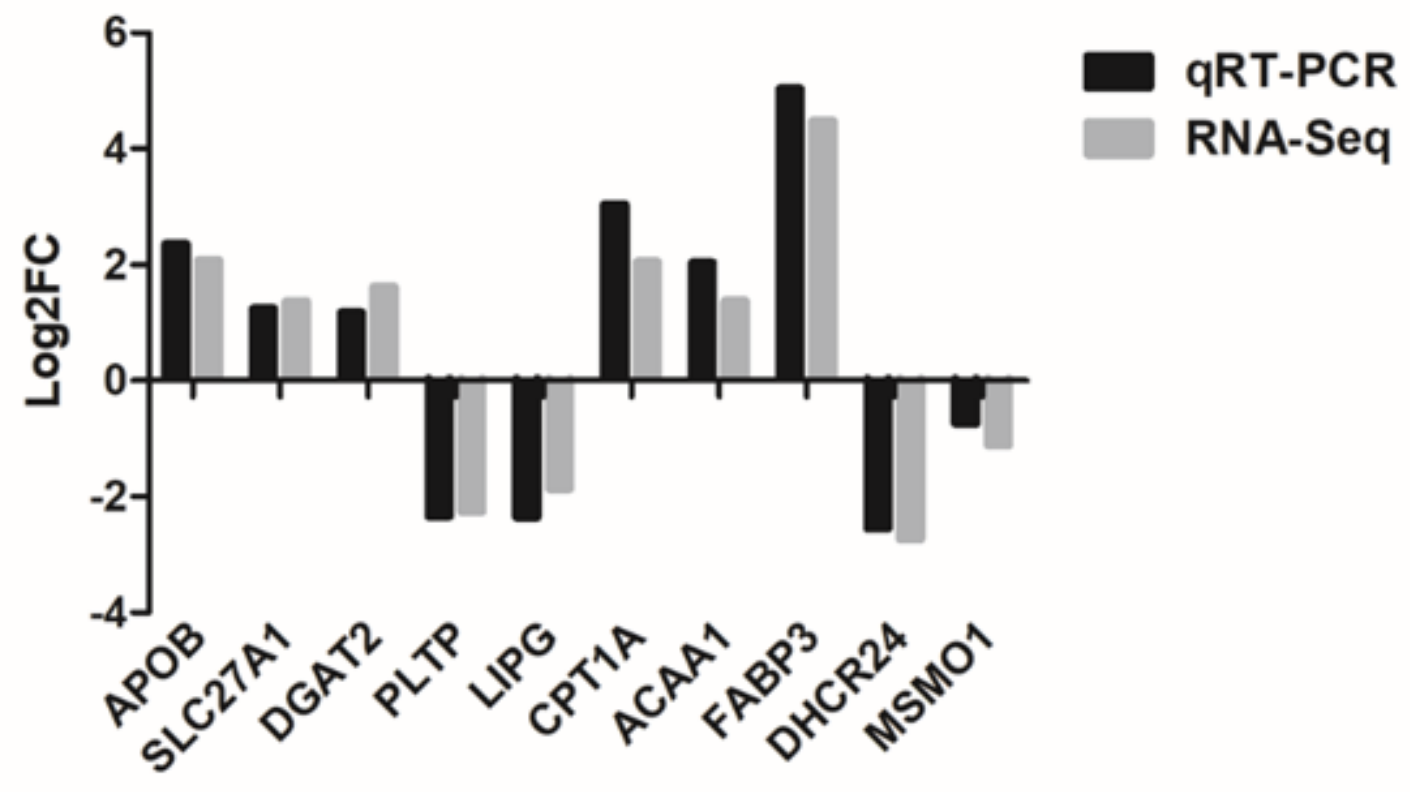

Figure 4 
Results of qPCR validation.

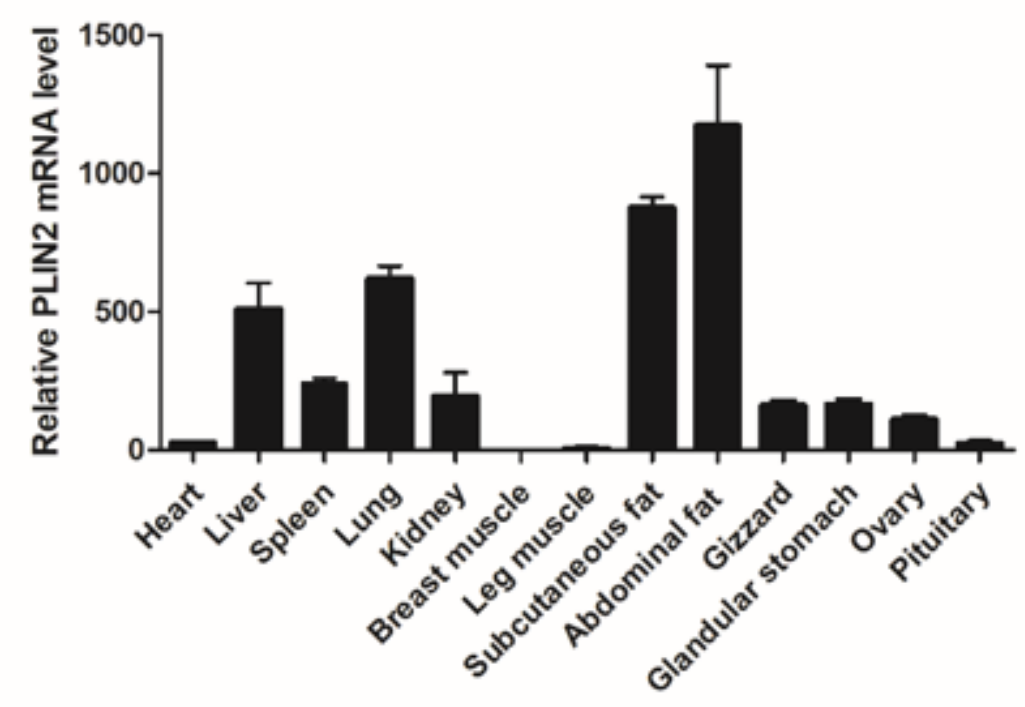

Figure 5

Tissue expression profile of PLIN2 in 150-day Daheng broilers. 


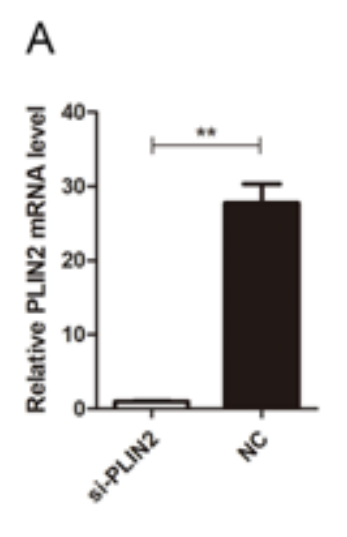

$\mathrm{E}$

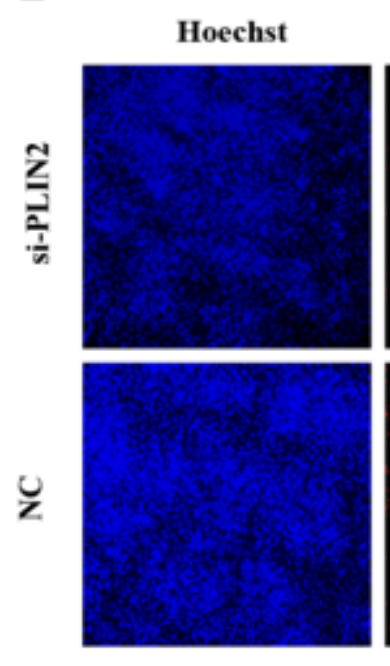

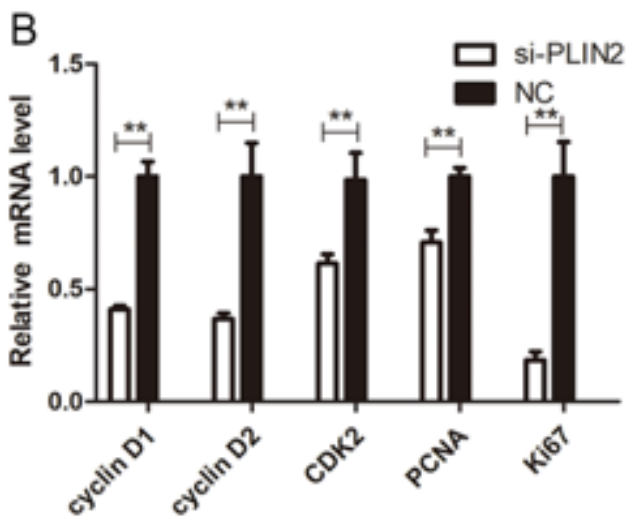

$\mathrm{D}$

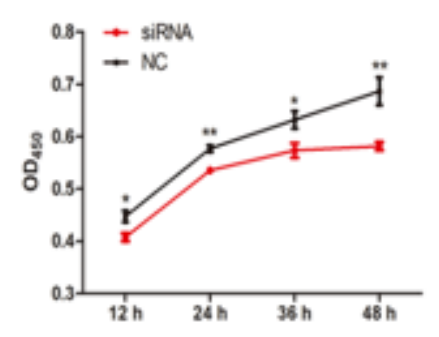

$\mathrm{F}$

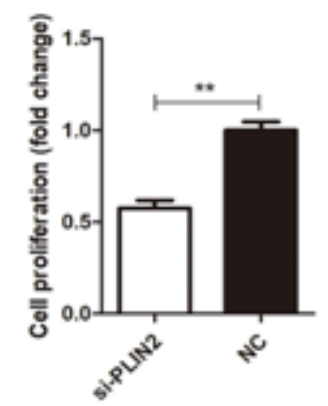

\section{Figure 6}

Interference of PLIN2 inhibits the proliferation of chicken intramuscular preadipocyte proliferation. (A) Confirmation of interference efficiency of the PLIN2 gene. (B) The mRNA expression level of cyclinD1, cyclinD2, CDK2, PCNA and Ki67 in si-PLIN2 and NC groups. (C) The protein expression level of CDK2 after transfection with si-PLIN2 and NC. (D) CCK assays for the proliferation activity of chicken intramuscular preadipocyte after transfection with si-PLIN2 and NC at $12 \mathrm{~h}, 24 \mathrm{~h}, 36 \mathrm{~h}$ and $48 \mathrm{~h}$. (E) si-NC. (E) EdU assays for chicken intramuscular preadipocyte after transfection with si-PLIN2 and NC (100x magnification). EdU (red) fluorescence represents proliferation. Hoechst (blue) fluorescence represents nuclei. $(F)$ The percentage of EdU stained cells to total cells. ${ }^{*} \mathrm{P}<0.05 ;{ }^{\star *} \mathrm{P}<0.01$. 
A

B
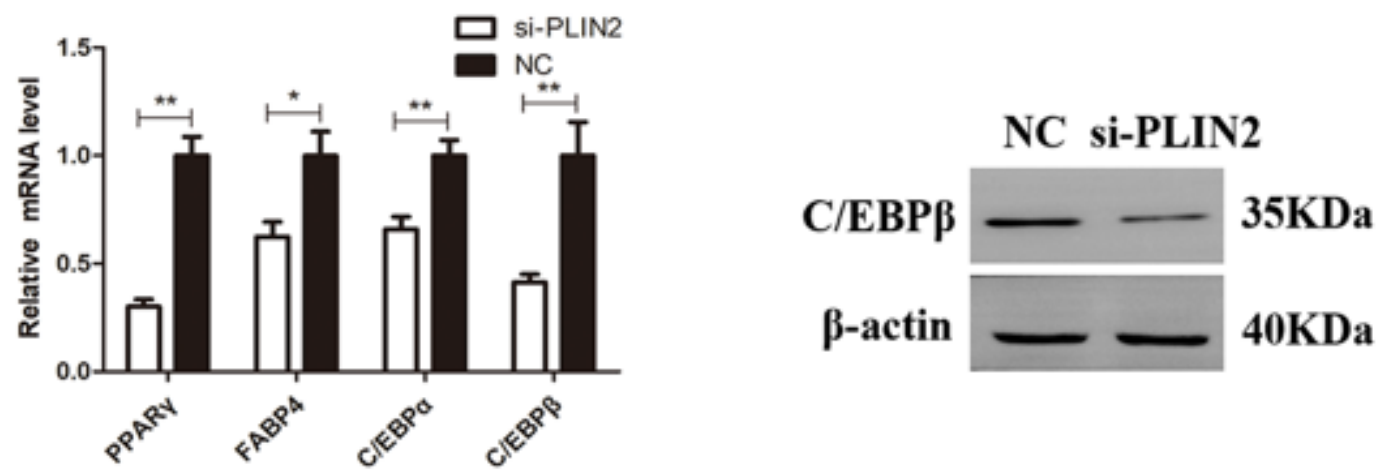

C

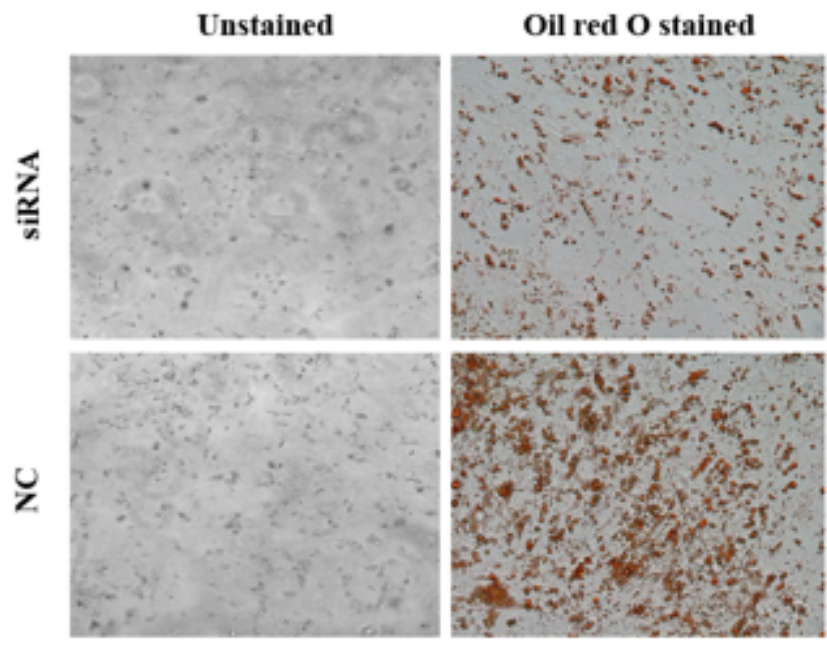

D

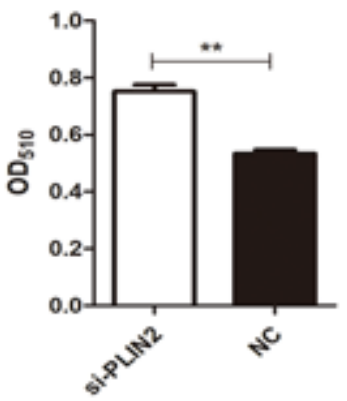

Figure 7

Interference of PLIN2 inhibits the differentiation of chicken intramuscular preadipocyte. (A) The mRNA expression level of PPARY, FABP4, C/EBPa and C/EBP $\beta$ in si-PLIN2 and NC groups. (B) The protein expression level of C/EBP $\beta$ after transfection with si-PLIN2 and NC. (C) Oil Red $O$ staining of intramuscular adipocytes in the fifth day after IBMX-DEX-INS-Oleate induction (100x magnification)). (D) Differentiation of adipocytes measured by spectrophotometric analysis. ${ }^{*} P<0.05 ;{ }^{*} \mathrm{P}<0.01$. 
A

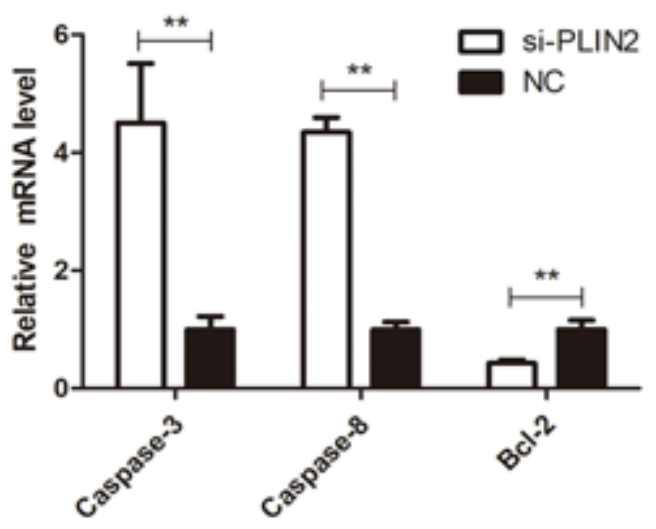

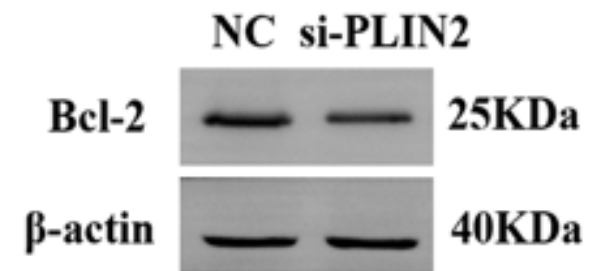

C

DAPI

PI

Merge
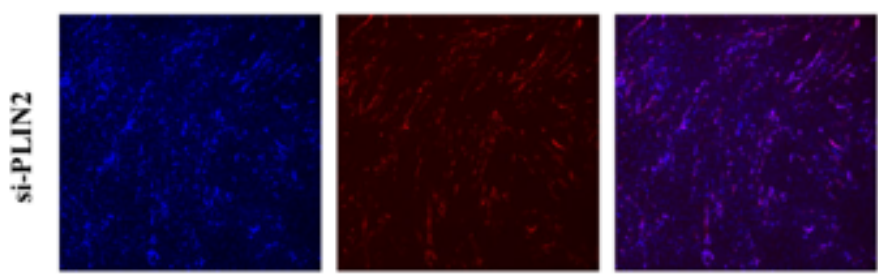

D

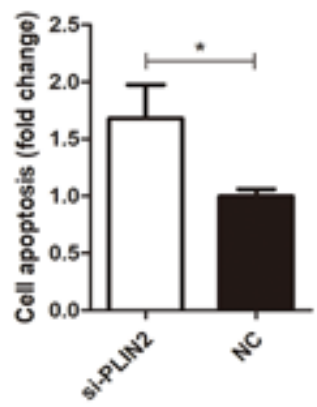

Figure 8

Interference of PLIN2 promotes the apoptosis of chicken intramuscular preadipocyte. (A) The mRNA expression level of caspase-3, caspase-8 and Bcl-2 in si-PLIN2 and NC groups. (B) The protein expression level of Bcl-2 after transfection with si-PLIN2 and NC groups. (C) Effects of the PLIN2 on the apoptosis of chicken intramuscular preadipocyte, determined by propidium iodide (PI) and DAPI double-staining (100x magnification). D. The percentage of PI stained cells to total cells. ${ }^{\star} \mathrm{P}<0.05 ;{ }^{\star \star} \mathrm{P}<0.01$.

\section{Supplementary Files}

This is a list of supplementary files associated with this preprint. Click to download.

- Table1.pdf 